\title{
La igualdad y no discriminación de las personas con discapacidad intelectual en la Educación Superior
}

\section{Equality and non-discrimination of people with intellectual disabilities in Ecuadorian Higher Education}

Fátima Piedad Gutiérrez-Mejía

fatima.gutierrez@psg.ucacue.edu.ec

Universidad Católica de Cuenca, Cuenca

Ecuador

https://orcid.org/0000-0003-1622-9291

Cecilia Ivonne Narváez-Zurita

inarvaez@ucacue.edu.ec

Universidad Católica de Cuenca, Cuenca

Ecuador

https://orcid.org/0000-0002-7437-9880

Cornelio Agustín Borja-Pozo

cborjap@ucacue.edu.ec

Universidad Católica de Cuenca, Cuenca

Ecuador

https://orcid.org/0000-0002-6361-2720

Juan Carlos Erazo-Álvarez

jcerazo@ucacue.edu.ec

Universidad Católica de Cuenca, Cuenca

Ecuador

https://orcid.org/0000-0001-6480-2270

Recibido: 14 de noviembre de 2019

Aprobado: 15 de diciembre de 2019 


\title{
RESUMEN
}

En este artículo se identifica que en lo que respecta a legislación tanto internacional como nacional que garantiza el derecho a la educación superior de las personas con discapacidad intelectual se han realizado avances significativos; sin embargo, aún queda un largo camino por recorrer pues es necesario que esta igualdad formal prevista de los diferentes cuerpos normativos se ejecute en las instituciones de educación superior (IES) en virtud de que solo la práctica de las mismas permitirá el ejercicio y goce del derecho aludido, lo contrario discrimina y convierte a la Constitución e instrumentos internacionales en poesía lírica, en utopía, en una meta a alcanzar, más no en una realidad, situación que desdice lo manifestado en la Constitución, referente a que Ecuador es un país incluyente.

Descriptores: Igualdad; Inclusión; Discriminación; Discapacidad intelectual; Educación superior.

\begin{abstract}
This article identifies that in terms of both international and national legislation that guarantees the right to higher education of people with intellectual disabilities, significant progress has been made; However, there is still a long way to go since it is necessary that this planned formal equality of the different regulatory bodies be executed in higher education institutions (HEls) because only their practice will allow the exercise and enjoyment of the right alluded to, the opposite discriminates and converts the constitution and international instruments into lyric poetry, utopia, a goal to be achieved, but not a reality, a situation that contradicts what is stated in the constitution, referring to the fact that Ecuador is an inclusive country.
\end{abstract}

Descriptors: Equality; inclusion; Discrimination; People with intellectual disabilities; Higher Education.

\section{INTRODUCCIÓN}

Previo a conceptualizar la teoría del Derecho Constitucional, es necesario conocer que hasta mediados del siglo XX aún se defendían postulados del derecho positivo, el que preveía a la ley como fuente del derecho, a esto se le conoce como el principio de legalidad. El Derecho Constitucional cambia este paradigma, así, en Latinoamérica las 
constituciones pasan a ser el eje central del ordenamiento jurídico que contienen derechos fundamentales y principios que son de obligatorio cumplimiento por parte del Estado, además, todas las ramas del Derecho se sujetan a la norma suprema, siendo entonces ésta el límite para el legislador y quien tenga capacidad normativa, por lo tanto, el ordenamiento jurídico de un país, se subordina a los preceptos constitucionales (Llano, 2017).

La Constitución del Ecuador del año 2008, en su parte dogmática tiene un catálogo de derechos humanos y de principios de obligatoria aplicación para el ejercicio de los mismos. Por lo expuesto, es necesario conocer ¿Qué son los principios de aplicación de los derechos y cuál es su propósito? los principios son normas jurídicas que tienen como propósito interpretar cualquier disposición normativa del ordenamiento jurídico y aplicarla en el caso concreto para garantizar el ejercicio de todos los derechos constitucionales (Aguilar, et al., 2009).

En la Constitución ecuatoriana el principio de la igualdad y no discriminación tiene tres dimensiones, la igualdad formal, la igualdad material y la no discriminación: la igualdad formal consiste en tratar igual a los iguales y diferente a los diferentes, en este tipo de igualdad está permitido un trato diferente si se encuentra normado en la ley. La igualdad material, es aquella que mira la realidad de la persona, su caso concreto a fin de proteger su diferencia, para garantizar que goce y ejerza sus derechos en igualdad. La no discriminación, hace referencia a la prohibición de cualquier acto que distinga, restrinja, disminuya o excluya a una persona el goce y ejercicio de sus derechos (Comité de Derechos Humanos, 1989).

Además, se precisa aquí que el más alto deber del Estado es garantizar a las personas con discapacidad un trato prioritario y especializado en el goce y ejercicio de sus derechos constitucionales. Esto incluye a la educación como un derecho humano, garantía de igualdad, inclusión, automomía e independencia para alcazar una vida digna; asegura empleo, alimentación, salud, vivienda y desarrollo de la personalidad (Asamblea Nacional Constituyente, 2008). 
Sin embargo, por décadas las universidades han estado concebidas como centros de transmisión y generación de conocimientos, teniendo únicamente como fin alcanzar la exelencia académica; situación que no permite a las universidades centrarse en las personas con discapacidad (Alcantud, Avila, y Asensi, 2000). Ahora bien, en la constitucionalización ecuatoriana, se garantiza que todas las personas son iguales en dignidad y derechos; por tanto, el derecho a la educación superior antes dirigido solo para los excelentes y competitivos, en la actualidad debe obligatoriamente ser garantizado para las personas con discapacidad intelectual en igualdad de oportunidades, conforme la normativa internacional, constitucional e infraconstitucional (Arteaga, 2019).

Por lo expuesto, el presente trabajo, busca contrastar si lo dispuesto en los instrumentos internacionales, así como en la Constitución de la República del Ecuador, Ley Orgánica de Discapacidades y Ley Orgánica de Educación Superior, en la práctica se cumplen dentro de las Universidades, y se garantiza a las personas con discapacidad intelectual el acceso a la educación en igualdad de condiciones y oportunidades.

\section{DESARROLLO}

\section{El derecho a la igualdad y no discriminación en el ámbito nacional e internacional}

La Declaración Universal de los Derechos Humanos proclama que "todos los seres humanos somos iguales en dignidad y derechos" (Declaración Universal de los Derechos Humanos, 1948). Cabe aquí preguntarse: ¿Las personas tienen las mismas oportunidades de educarse, desarrollar destrezas y aptitudes?, ¿Todas las personas alcanzan en un momento determinado la autonomía e independencia que permitan realizar y cumplir el desarrollo de la personalidad y vida digna? Antes de abordar qué es la igualdad en dignidad y derechos, de manera breve es necesario remontarse a sus orígenes y evolución. 
Una mirada a las sociedades antiguas testifica que era el propio derecho y su sistema jurídico, el que avalaba las desigualdades entre seres humanos, pues, cada persona nacía con un status, es decir, con un derecho que le otorgaba capacidades o facultades y ciertas incapacidades, éstas les eran implícitas por pertenecer a determinada clase social, no era algo que se alcanzaba o ganaba, sino que dependía del nacimiento y de otros hechos que no podían ser controlados por el individuo (Rabbosi, 1990).

Por ejemplo, en los sistemas jurídicos antiguos, la mujer noble servía de moneda de cambio para sellar pactos políticos, tenía ciertos privilegios como acceso a la educación, el cuidado y educación de los hijos, organización de los empleados de la casa. A la mujer plebeya en cambio, se le asignaban tareas exclusivamente domésticas, si era soltera o viuda se consideraba una carga (Duarte y García, 2016) Los niños, no tenían un derecho de infancia, acceso a la educación, al juego, eran víctimas de abuso, maltratos físicos y sexuales. Es a mediados del siglo XX que se los empieza a considerar personas (Justel, 2012); De la esclavitud no existen datos precisos; sin embargo, en el Antiguo Egipto los hebreos fueron prisioneros de los egipcios y liberados en el año 152 a. de c. (Ricciardi, Hurault, y Rodás, 2007), la esclavitud estaba ligada a las guerras, el pueblo conquistador, volvía esclavo al conquistado (Ramírez, 2014).

Por lo expuesto, se diría entonces que, en un principio, los seres humanos no eran iguales ni en dignidad, ni en derechos; la primera noción de igualdad aparece en el año 539 AC con el Emperador Ciro el Grande, quien al conquistar Babilonia liberó a todos los esclavos (Ibídem). En forma posterior filósofos como Platón, sostenían que la igualdad es la distribución en partes iguales. Para Aristóteles, la igualdad consiste en igualdad para los iguales y desigualdad para los desiguales o lo que se conoce como la igualdad de trato (Barreré, 2003).

Esta fórmula de la igualdad, aunque sencilla a primera vista resulta controvertida, aplicarla, implica realizar comparaciones, razonamientos y decisiones, las que ameritan una selección de los sujetos comparables y de los datos que van a considerarse 
relevantes con el fin de emitir un juicio comparativo de igualdad, juicio que estará basado en diferentes criterios de justicia, que al ser aplicados por un sujeto, corren el riesgo de fundarse en las ideologías parcializadas de la persona que tiene el poder para otorgar la igualdad de trato y por tanto esta igualdad podría convertirse en una aplicación subjetiva, basada en juicios de valor y no en juicios de hecho (Ibídem). Ante la problemática expuesta, filósofos y técnicos señalan que la igualdad consiste “... en todos los aspectos relevantes los seres humanos deben ser considerados y tratados de igual manera, es decir, de una manera uniforme e idéntica, a menos que haya una razón suficiente para no hacerlo (...)" (Rabbosi, 1990, p. 2).

De la revisión de las convenciones para erradicar la discriminación racial, de género y por discapacidad entre otras, atinentes a garantizar la igualdad, se evidencia que estas regulaciones comunes y universales, tienen como base, las diferencias propias, que en un determinado momento histórico fueron permitidas por el sistema jurídico, son estas diferencias las que originan luchas sociales de los grupos de personas históricamente discriminados y en consecuencia la generación de normativa internacional que busca la igualdad de derechos (Defensoría del Pueblo del Ecuador [DPE], 2015).

Un útil ejemplo de lo expuesto, es que las mujeres independientemente de su condición civil y social puedan en igualdad de condiciones, acceder a educación, trabajo, ocupar cargos y funciones públicas, derecho al voto, derecho a su sexualidad y su cuerpo, entre otros. (Convención sobre la eliminación de todas las formas de discriminación contra la mujer, 1979); que los niños se eduquen, vivan en un ambiente sano, que tengan una identidad, se impone un límite de edad para trabajar; se prohíbe su trabajo en lugares que pongan en riesgo su integridad personal (Convención sobre los Derechos del Niño, 1990).

Los instrumentos internacionales arriba referidos, plantean conceptos de discriminación y la necesidad de acoger medidas legislativas o de cualquier otra índole hasta lograr la anhelada igualdad en dignidad y derechos, tienen como base fundamental: primero, eliminar la desigualdad basada en diferentes características como raza, género, 
orientación sexual, edad, lugar de nacimiento, condición social, religión, entre otros, a los que actualmente se los conoce como aspectos sospechosos de discriminación, segundo prohibir la discriminación y por último generar acciones que garanticen que estos grupos que históricamente fueron considerados objetos se conviertan en sujetos de derechos (DPE, 2015).

De lo expuesto, se desprende entonces que un trato diferente o un ajuste razonable únicamente está permitido para asegurar a una persona el goce y ejercicio de un derecho, cuando esta persona por diferentes motivos como los antes aludidos, no ha tenido las mismas oportunidades que otra; es decir, en los hechos, no ha accedido y gozado de los derechos; generalmente se refiere, a quienes están considerados dentro de los criterios sospechosos de discriminación. Este trato diferenciado, ajuste razonable o medida afirmativa es temporal y se otorgan para impulsar la igualdad.

Con la constitucionalización del derecho, los instrumentos internacionales fueron insertándose en las constituciones de los diferentes países. Así en Ecuador, en su norma suprema del año 2008, el principio de igualdad y no discriminación, se inserta como principio de aplicación de los derechos, además se norma, la obligación de realizar medidas de acción afirmativa en favor de los titulares de derecho que se encuentran en situación de desigualdad, también se hace alusión al derecho a la igualdad como derecho autónomo (DPE, 2015).

Como principio de aplicación, la igualdad es una norma jurídica que debe ser incluida en el ejercicio y goce de todos los derechos constitucionales, brinda la posibilidad de interpretar la ley para utilizarla en la realidad fáctica de los sujetos (Aguilar, et al., 2009). Por otra parte, la Constitución ecuatoriana contextualiza a la igualdad como derecho autónomo y norma sus diferentes dimensiones, así, se refiere a la igualdad formal, que es la versión clásica de la igualdad de Aristóteles, teniendo en cuenta que un trato diferenciado solo está permitido si la ley lo dispone (Barreré, 2003).

Además, se encuentra la igualdad material, la que reconoce que los seres humanos son únicos y diferentes; y, sin importar las diferencias, se debe garantizarles igualdad de 
oportunidades para el ejercicio y goce de sus derechos (DPE, 2015). Finalmente está la prohibición de la discriminación, que refiere a la prohibición de cualquier acto que distinga, excluya, prefiera o restringa el goce y ejercicio de derechos humanos (Aguilar, et al., 2009).

\section{Las personas con discapacidad y el ejercicio y goce de su derecho a la Educación Superior, aplicando el principio de igualdad y no discriminación}

La evolución del sistema jurídico y de la sociedad en su conjunto en lo que respecta a las personas con discapacidad ha pasado por tres momentos históricos: El modelo de prescindencia, el cual atribuía la discapacidad al castigo de Dios por los pecados cometidos, en este modelo era obligación del Estado exterminar a las personas con discapacidad pues se las consideraba inútiles y una carga para él y el grupo familiar. En Roma a partir del siglo II d. C. la praxis del infanticidio fue cambiada por la utilización de las personas con discapacidad para el entretenimiento de las fiestas de los Emperadores Romanos (Palacios, 2008).

A inicios del mundo moderno, aparece el modelo rehabilitador, en éste la discapacidad ya no tiene una causa religiosa, sino científica pues está basada en un estado de salud o enfermedad, motivo por el cual se busca rehabilitar a la persona, es decir, que pase de un estado de inutilidad a un estado de normalidad. En el momento actual nos encontramos en el modelo social el que sustenta que la discapacidad no tiene una causa ni religiosa, ni científica, sino social; es la sociedad quien ha construido una cultura de lo inútil que es una persona con discapacidad (ibídem). El modelo social busca romper estas construcciones sociales, mentales y culturales con la finalidad de desarrollar las capacidades y habilidades de la persona con discapacidad y su inclusión, independencia y autonomía personal (Maldonado, 2013).

El modelo social propone el concepto de educación inclusiva y la importancia de que sean las aulas educativas las que se acoplen a las necesidades de la persona con discapacidad, garantizándoles una educación en el sistema regular y enfatizando que la 
educación especial debe ser una excepcionalidad (Palacios, 2008). La Educación inclusiva, es una educación centrada en la persona y su necesidad de aprender utilizando diferentes recursos técnicos y metodológicos, que compensen dichas dificultades (García, 2017), es decir, una educación que reconoce la diversidad y equidad. Consiste en lograr que los centros educativos, sus docentes, metodológías y técnicas de aprendizaje se adapten a la persona con discapacidad (Clavijo y Bautista, 2009).

El derecho a la Educación es un derecho humano intrínseco, permite incluirse en la sociedad, salir de la pobreza, es garantía de autonomía e independencia; en definitiva, es el vehículo que permite a los seres humanos el ejercicio y goce de una vida digna y la materialización del proyecto de vida (Aguilar, et al., 2009). En este sentido, la Constitución del Ecuador señala que la educación es un derecho irrenunciable y un deber inexcusable del Estado, que se ejerce a lo largo de la vida, garantizado hasta la educación superior, siendo su obligación y responsabilidad definir y ejecutar políticas que permitan el acceso, permanencia y titulación para todas las personas que se encuentran en su territorio, incluyendo a las personas con discapacidad intelectual (Asamblea Nacional Constituyente, 2008).

En este punto se han definido a la igualdad y no discriminación como principio y derecho; y, a la educación como un derecho humano, se entiende que el mismo es indispensable para lograr autonomía, independencia, una vida digna y la consecución del proyecto de vida.

Corresponde entonces aterrizar estos conceptos, a fin de tener claro que una persona con discapacidad para estar en igualdad de condiciones necesita un trato diferenciado y/o un ajuste razonable, pues, no solo que, históricamente no ha tenido las mismas oportunidades, sino que además, como persona con discapacidad intelectual presenta dificultades significativas en su área cognitiva, es decir en el "[...] razonamiento, planificación, solución de problemas, pensamiento abstracto, comprensión de ideas 
complejas, aprender con rapidez y aprender de la experiencia [...]" (Hurtado y Agudelo, 2014, p. 47, 48), así como en su área adaptativa (ibídem).

Actualmente se considera que la discapacidad intelectual no puede ser medida únicamente por el coeficiente intelectual (C.I) sino también por las habilidades sociales y practicas aprendidas que le permiten desenvolverse con autonomía en su vida diaria (Schalock, 2009).

Centrándose en la educación superior, en sus inicios no fue pensada ni concebida para personas con discapacidad, pues ella es fuente de tramisión de conocimientos, de competitividad, de excelencia; constructo mental, que se convierte en la primera barrera u obstáculo para la educación superior de una persona con discapacidad, por tanto, es necesario deconstruir este concepto para dar paso a la inclusión (Alcantud, et al., 2000).

Ecuador como Estado constitucional de derechos a través de sus normativas (Tabla 1) garantiza el derecho a la educación superior inclusiva de las personas con discapacidad.

\section{Tabla 1}

Disposiciones normativas que garantizan la inclusión a la educación de las personas con discapacidad.

\section{Cuerpo normativo}

Declaración Universal de los Derechos Humanos

Convención sobre los derechos de las personas con 24.2.c; 24.4.5 discapacidad.

Constitución de la República del Ecuador

Ley Orgánica de Discapacidades, Sección III

Ley Orgánica de Educación Superior

\section{Articulado}

26.1 .2

$26 ; 28 ; 47.7 ; 343 ; 350$

$27,28,33,34$

$4,5,7,71$ 
La normativa aludida hace referencia a la obligación del Estado de garantizar, es decir, de hacer, obligación que implica crear políticas públicas, normar mecanismos y realizar diferentes acciones (Oficina del Alto Comisionado de las Naciones Unidas para los Derechos Humanos [ACNUDH], 2012). Estas medidas se encuentran contempladas como mecanismos o ajustes razonables los que consisten en adaptaciones curriculares, ayudas técnicas, textos en braille, comunicación táctil (para personas no videntes), macro tipos para personas con visión baja, medios de voz digitalizada, el uso de tecnologías, lenguaje de señas, entre otros y buscan que las personas con discapacidad a través de ellas ejerzan y gocen de su derecho a la educación (Convención Internacional sobre los derechos de las personas con discapacidad, 2006). Los ajustes razonables o mecanismos para hacer realidad la educación superior de las personas con discapacidad es diversos, el presente trabajo se enfoca en las adaptaciones curriculares, pues las nuevas conceptualizaciones de la discapacidad intelectual sostienen que los apoyos individualizados apropiados permitirán que la persona con discapacidad intelectual se desarrolle adecuadamente en diferentes ámbitos, lo que con seguridad les permitirá una mejor calidad de vida (Schalock, 2009). Corresponde entonces definir qué son las adaptaciones curriculares y qué es el currículo. El currículo es el proyecto educativo en que constan los conocimientos y experiencias de aprendizaje necesarios para que una persona se forme como un profesional, esta profesión siempre estará atada a las necesidades de la sociedad, el currículo es cambiante, se adapta a los avances científicos, tecnológicos, las necesidades sociales y los estudiantes, en él se planifican las acciones de los docentes, estudiantes y universidad (García, 2017). Previo a la realización de una modificación curricular es necesario una valoración psicopedagógica; pues ésta permite determinar si un estudiante posee las competencias básicas para cursar la carrera universitarita; en función de los resultados, se planifican las ayudas personalizadas del estudiante (Ibídem). 
Existen diferentes tipos de adaptaciones curriculares: las adaptaciones de acceso al currículo, que se realizan de manera previa a la adaptación de la malla curricular y con ellas se puede evitar la realización de adaptaciones significativas, hacen referencia al acceso al espacio físico, como: ubicar al estudiante con discapacidad en los primeros asientos. Las adaptaciones propiamente curriculares, modifican los “(...) objetivos, contenidos, criterios y procedimientos de evaluación, y en las actividades y metodología para atender las diferencias individuales de los alumnos (...)" (Alcantud, et al., 2000, p.92), dentro de ellas se encuentran las adaptaciones no significativas se realizan en la metodología, técnica y estrategias del proceso enseñanza aprendizaje, tienen relación con los tiempos y recursos utilizados; y, las adaptaciones curriculares significativas suprimen conceptos básicos de enseñanza tanto en los objetivos, contenidos y criterios de evaluación (ibídem).

\section{Análisis de casos prácticos que permiten determinar el cumplimiento de las medidas de acción afirmativa (ajustes razonables adaptaciones curriculares) para garantizar la igualdad y no discriminación de las personas con discapacidad intelectual}

De lo expuesto se desprende que las adaptaciones curriculares, van desde recomendaciones en el espacio físico, utilización de recursos materiales y tecnológicos, aplicación de diferentes métodos, técnicas y estrategias de enseñanza aprendizaje; hasta la modificación o supresión de conceptos básicos en los objetivos y contenidos de una materia o asignatura (Alcantud, et al., 2000).

En este sentido, corresponde analizar si las Instituciones de Educación Superior (IES), cuentan con el equipo técnico que esté en condiciones de realizar una valoración psicopedagógica a fin de determinar las necesidades específicas de aprendizaje de un estudiante con discapacidad intelectual; si los docentes universitarios en coordinación con el equipo multidisciplinario de las universidades preparan las adaptaciones 
curriculares del estudiante con discapacidad intelectual en función de su necesidad individual.

Para lograr este objetivo se analizará tres demandas de acción de protección de estudiantes con discapacidad intelectual, pertenecientes a diferentes IES de la ciudad de Cuenca, estos casos concretos, servirán para conocer las barreras que enfrenta un estudiante con discapacidad intelectual.

La primera acción de protección, tuteló los derechos de un joven con una discapacidad intelectual del 30\%, quien ingresó al curso de nivelación en la carrera de Orientación Familiar a fin de obtener un cupo, la universidad fue advertida respecto de la discapacidad intelectual; sin embargo, no realizó acción alguna a fin de garantizar el acceso a la carrera universitaria. El argumento de la IES para justificar la falta de un trato diferenciado fue que desconocía la discapacidad intelectual del estudiante, aunque la misma se evidencia en la cédula de identidad. La acción de protección fue declarada con lugar disponiéndose la asignación del cupo y la correspondiente matrícula (Acción de Protección, 2018). De los hechos fácticos se observa que la IES, no cuenta, con un filtro mínimo, una alerta que permita identificar el ingreso de una persona con discapacidad intelectual.

A continuación, se expone el caso de una joven con discapacidad intelectual del 33\%, quien estudiaba la carrera de Gastronomía, cursó y concluyó de manera favorable el segundo ciclo, aunque reprueba por segunda ocasión en la materia de COCINA III en el tercer nivel, motivo por el cual, solicitó la autorización de una tercera matrícula que le fue negada, además de aquello se indica que la estudiante jamás recibió adaptaciones curriculares. La defensa de la IES fue que el cambio de la malla curricular fue realizado por el Consejo de Educación Superior, por tanto, no podía abrir un curso solamente para la joven y en consecuencia debía iniciar sus estudios con la nueva malla; en cuanto a las adaptaciones curriculares no han sido realizadas porque la madre de la estudiante no ha indicado a la IES como deben realizarse las mismas. La Acción de 
Protección fue declarada con lugar ordenándose la concesión de la matrícula y la aplicación de adaptaciones curriculares (Acción de Protección, 2018).

En el presente caso la IES a pesar de tener conocimiento que contaba entre su alumnado con una estudiante con discapacidad intelectual, no realizó ninguna evaluación sicopedagógica, para conocer el tipo de ayudas o adaptaciones que requería la estudiante con discapacidad, contrariando con esta actuación, el artículo 34 de la Ley Orgánica de Discapacidades; y lo más grave trasladando a la madre de la persona con discapacidad, su obligación de garantizar en su calidad de delegatario del Estado la prestación de un servicio público conforme lo dispone el Art. 11 numeral 9 de la Constitución. En este caso particular no aplicó el trato diferenciado previsto en la Constitución, a fin de garantizarle una educación inclusiva que desarrolle sus habilidades y potencialidades previstas en las disposiciones normativas aludidas en la tabla1.

El último caso que se analiza, es de un joven con discapacidad intelectual del $48 \%$ que venía cursando su tercer año de estudios superiores en la Carrera de Artes Teatrales, dicho estudiante no pudo continuar sus estudios pues agotó su tercera matricula en la asignatura Dirección 1. La madre del estudiante hace hincapié en que a pesar de su lucha la universidad no realizó adaptaciones curriculares. El argumento de la Universidad, fue que se le realizó al estudiante con discapacidad intelectual las correspondientes adaptaciones curriculares, así como, la evaluación sicopedagógica. La Acción de Protección fue declarada con lugar en segunda instancia (Acción de Protección, 2019).

De la documentación aparejada por la IES, se observa que, en octubre del año 2013, cuando el estudiante inició la carrera, la universidad le realizó un informe psicológico, evaluación que confirma la discapacidad intelectual, déficit de atención e hiperactividad; y refiere que el estudiante tiene dificultades para realizar trabajos que requieren motricidad fina, se distrae y cansa con facilidad, presenta problemas al recordar las tareas y dificultad en el contacto con la gente. 
Acogiendo el informe psicológico, la universidad dirigió a los docentes algunas recomendaciones, como, por ejemplo: llamar al estudiante por su nombre de manera sutil cuando éste se encuentre distraído; darle consignas claras, cortas y no confusas; acostumbrar al estudiante a revisar sus trabajos o exámenes antes de entregarlos; entre otras. A estas recomendaciones, Alcantud et al. (2000) las denominan adaptaciones de acceso al currículo, sin embargo, este tipo de adaptaciones no son las únicas previstas, pues existen las adaptaciones propiamente curriculares que pueden ser significativas o no significativas.

Los informes docentes, dan cuenta de las capacidades y dificultades del estudiante, pues, los mismos señalan que el estudiante realiza un enorme esfuerzo por alcanzar los objetivos de aprendizaje, así como de sus dificultades motrices y cognitivas, las cuales le impiden recordar y mantener el orden en las series de ejercicios físicos que forman parte de la malla curricular, concluyendo que el estudiante necesita de otros logros de aprendizaje, adoptando otra metodología; a su ritmo, en tiempo más largos y de carácter personalizado, puesto que el interés y el sobre esfuerzo era notorio (Acción de Protección, 2019).

Pese a las recomendaciones docentes, la IES nunca las acogió, demostrando con aquello, que, de parte de la universidad, no existió acción alguna que pueda considerarse como adaptación curricular o ajuste razonable. De acuerdo a Alcantud et al. (2000) dichas adaptaciones serían las propiamente curriculares no significativas, las mismas que de haber sido adoptadas, hubiesen permitido a la IES analizar y evaluar si las recomendaciones impartidas eran suficientes o se requería de alguna adaptación curricular significativa, con el propósito de superar sus dificultades y potencializar sus habilidades.

Lo expuesto, es una muestra de que lo previsto en la doctrina y en el artículo 34 de la Ley Orgánica de Discapacidades, referente a la evaluación psicopedagógica, debe ser previa y sobre todo debe permitir planificar las estrategias y necesidades individuales del estudiante con discapacidad intelectual, siendo indispensable un seguimiento de los 
avances y dificultades. Contando con un equipo multidisciplinario y especializado que coordine con los docentes y puedan establecer con precisión, en qué momento se hace necesaria la aplicación de adaptaciones significativas o no significativas, para garantizar el derecho a la educación superior en igualdad de oportunidades.

\section{METODOLOGÍA}

En primera instancia se recopiló y revisó información bibliográfica relevante que permitió ubicar el tema en su proceso histórico y enfocarlo en la actualidad. Entre esta bibliografía se destaca la normativa nacional e internacional. Luego se procedió a buscar casos emblemáticos presentados como acción de protección para tutelar los derechos vulnerados; con los cuales se realizó un análisis de cada uno en contraste con la normativa citada previamente y sus conceptos relevantes.

En forma posterior se desarrolló unos breves aportes que permiten abrir un tema de debate interesante que todavía es poco atendido por los estudiosos de los derechos humanos en general y de los derechos de las personas con discapacidad en particular (Mogrovejo, Erazo, Pozo y Narváez, 2020).

\section{APORTES GENERADOS}

De lo expuesto se desprende que la igualdad no es un concepto rígido sino flexible, no se restringe a un trato identico para todos los seres humanos, sino más bien lo contrario, es un principio o valor que mira la realidad de cada persona, sus dificultades y diferencias, el lugar donde se desarrolla, lo cual permite analizar si corresponde o no, otorgarle un trato diferente, a través de acciones positivas que equiparen las condiciones de las personas con discapacidad intelectual, con el propósito de que éstas puedan ejercer y gozar sus derechos a plenitud. Para que estas acciones positivas no sean subjetivas $o$ arbitrarias se han normado en instrumentos internacionales y insertaándose en las constituciones de los Estados. 
Las personas con discapacidad, historicamente han sido consideras como una carga para el Estado, la sociedad y la familia, es decir, incapaces de estudiar, trabajar y aportar a la sociedad, siendo en un momento de la historia exterminadas, relegadas a activiades de entretenimiento y mendicidad.

La legislación ecuatoriana en su contenido formal brinda una protección integral para el ejercicio del derecho a la educación superior de las personas con discapacidad intelectual, sin restricción que limite o anule su acceso, permanencia, egreso y titulación. Sin embargo, la realidad de los estudiantes con discapacidad intelectual es contraria a las disposiciones normativas.

Los casos analizados evidencian que las universidades e institutos de educación superior en Ecuador no cumplen con sus obligaciones como representantes estatales, vulnerando y no garantizando el derecho a la educación superior en igualdad de oportunidades de las personas con discapacidad intelectual y en consecuencia su inclusión en la sociedad. La enunciación constitucional que asegura que Ecuador es un país inclusivo no es más que aún una meta a alcanzar (ver figura 1).

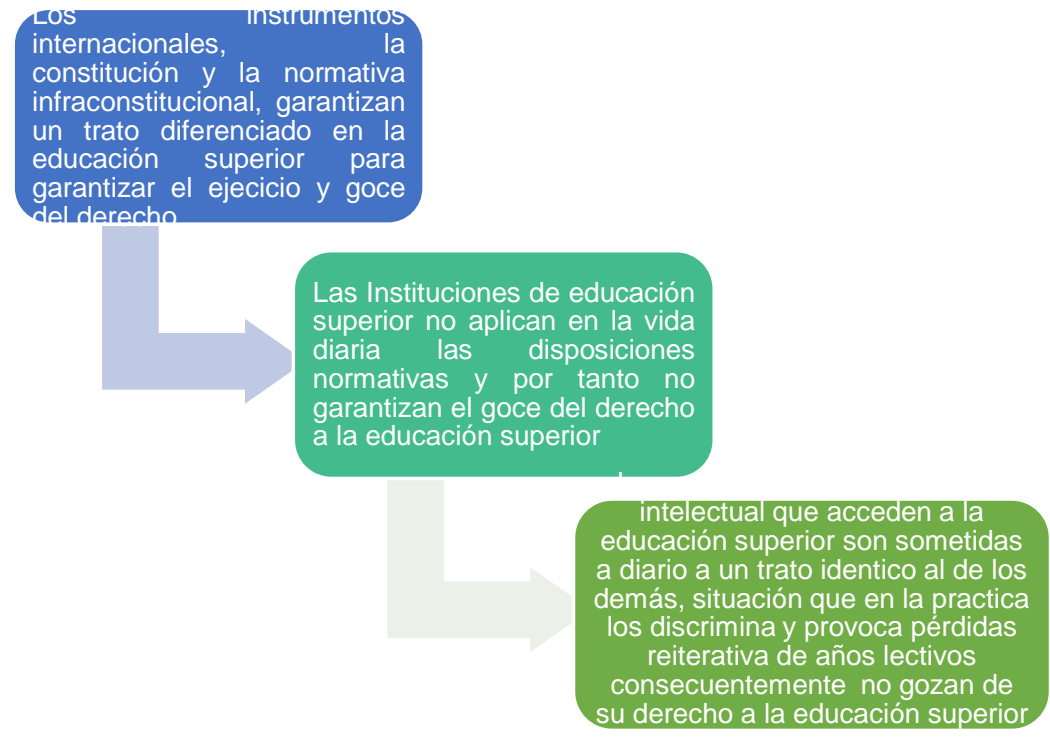

Figura 1. Vulneración del derecho a la educación superior en igualdad de oportunidades de las personas con discapacidad intelectual. (Elaboración propia). 


\section{REFERENCIAS CONSULTADAS}

1. Acción de Protección, 01333-2018-03875 (UNIDAD JUDICIAL CIVIL CUENCA 29 de Junio de 2018).

2. Acción de Protección, 01204-2018-05746 (Unidad Judicial de Familia, Mujer, Niñez y Adolescencia con Sede en el cantón Cuenca 12 de Octubre de 2018). Obtenido http://consultas.funcionjudicial.gob.ec/informacionjudicial/public/informacion.jsf

3. Acción de Protección, 01333-2018-03875 (Unidad Judicial Civil de Cuenca 24 de Agosto de 2018). Obtenido de http://consultas.funcionjudicial.gob.ec/informacionjudicial/public/informacion.jsf

4. Acción de Protección, 01333-2019-00475 (Sala de lo Civil y Mercantil de la Corte Provincial del Azuay 02 de Mayo de 2019). Obtenido de http://consultas.funcionjudicial.gob.ec/informacionjudicial/public/informacion.jsf

5. Aguilar, J., Avila, R., Benalcazar, P., Borja, A., Cordero, D., Dávalos, J., . . Silva, C. (2009). NUEVAS INSTITUCIONES DEL DERECHO CONSTITUCIONAL ECUATORIANO. Comunicaciones INREDH.

6. Aguilar, J., Avila, R., Benalcázar, P., Borja, A., Cordero, D., Dávalos, J., . . Silva, C. (2009). Nuevas instituciones del Derecho Constitucional ecuatoriano (Vol. 14).

(L. Á. (INREDH), Ed.) Comunicaciones INREDH. Obtenido de https://doi.org/10.18041/0121-3474/verbaiuris.38.1051

7. Aguilar, J., Ávila, R., Benalcázar, P., Borja, A., Cordero, D., Dávalos, J., . . Silva, C. (2009). Nuevas Instituciones del Derechos Constitucional Ecuatoriano (Vol. Serie Investigación \# 14). julio, Ecuador: Comunicaciones INREDH. Obtenido de https://www.inredh.org/archivos/pdf/constitucion_final.pdf

8. Alcantud, F., Avila, V., \& Asensi, M. (2000). La Integración de los estudiantes con discapacidad en los estudios superiores. Universidad de Valencia. Obtenido de https://oficinasuport.uib.cat/digitalAssets/108/108610_A4B3DF5Cd01.pdf

9. Alföldy, G. (1987). Historia Social de Roma. Ed. cast.: Alianza Editorial, S. A., Madrid, 1987, 1988, 1992, 1996.

10. Arteaga, A. (2019). Inclusión laboral de las personas con discapacidad. IUSTITIA SOCIALIS, 4(1), 16-38. doi:http://dx.doi.org/10.35381/racji.v4i1.536 
11. Artóteles. (1985). La Política, Vol.II. Madrid: Espasa, Calpe.

12. Asamblea Nacional Constituyente. (2008). Constitución de la República del Ecuador.

13. Asamblea Nacional Constituyente. (2008). Constitución de la República del Ecuador. Montecristi.

14. Asamblea Nacional Constituyente. (2008). Constitución de la República del Ecuador. Montecristi, Ecuador.

15. Ávila, R. (2012). Los derechos y sus garantías ensayos críticos. Quito, Ecuador: Centro de Estudios y Difusión del DerechoConstitucional (CEDEC).

16. Barreré, M. (2003). Igualdad y "discriminación postiva": un esbozo de análisis reórico conceptual. Vazco, España. Obtenido de https://dialnet.unirioja.es/servlet/articulo?codigo=759143

17. Carmona, E. (1994). El principio de igualdad material en la jurisprudencia del Tribunal Constitucional. Revista de estudios políticos, 1994 - dialnet.unirioja.es, 7.

18. Clavijo R, \& Bautista M. (2009). La educación inclusiva. Análisis y reflexiones en la educación superior ecuatoriana. Alteridad revista de educación, 15, 113-124. Obtenido de https://doi.org/10.17163/alt.v15n1.2020.09

19. Comité de Derechos Humanos. (1989). Observación General No. 18 "No discriminación". Obtenido www.acnur.org/fileadmin/Documentos/BDL/2001/1404.pdf

20. Convención Internacional sobre la Eliminación de todas las Formas de Discriminación Racial. (enero). Convención Internacional sobre la Eliminación de todas las Formas de Discriminación Racial. Alto Comsionado de las Naciones Unidas.

21. Convención Internacional sobre los derechos de las personas con discapacidad. (2006). Convención Internacional sobre los derechos de las personas con discapacidad. New York.

22. Convención sobre la eliminación de todas las formas de discriminación contra la mujer. (18 de Diciembbre de 1979). Convención sobre la eliminación de todas las formas de discriminación contra la mujer. Obtenido de https://www.ohchr.org/Documents/Professionallnterest/cedaw_SP.pdf 
23. Convención sobre los derechos de las personas con discapacidad. (2008). Convención sobre los derechos de las personas con discapacidad. Alto Comisionado de las Naciones Unidas.

24. Convención sobre los derechos de las personas con discapacidad. (2008). Convención sobre los derechos de las personas con discapacidad.

25. Convención sobre los Derechos del Niño. (1990). Convención sobre los Derechos del Niño. Oficina del Alto Comisionado de las Naciones Unidad.

26. Declaración Universal de los Derechos Humanos . (1948). París.

27. Declaración Universal de los Derechos Humanos. (10 de Diciembre de 1948). Declaración Universal de los Derechos Humanos. Declaración Universal de los Derechos Humanos. París. Obtenido de Recuperado de https://www.humanium.org/es/derechos-humanos-1948/

28. DPE. (Diciembre de 2015). A cerca de nosotros: Biblioteca Digital Especializada de la Defensoría del Pueblo. Obtenido de http://repositorio.dpe.gob.ec

29. Duarte, J., \& García, J. (2016). Igualdad, equidad de género y feminismo, una mirada histórica a la conquista de los derechos de las mujeres. (18), 107-158. Obtenido de http://dx.doi.org/10.18046/recs.i18.1960

30. Ecuador. Defensoría del Pueblo. (Diciembre de 2015). Soporte teórico para introducción a los derechos humanos. Quito, Ecuador: DPE. Obtenido de Recuperado de http://repositorio.dpe.gob.ec/handle/39000/2138

31. Ecuador. Defensoría del Pueblo. Coordinación Nacional de Protección Prioritaria. (2012). Guía de atención de casos de discriminación. Quito, Ecuador. Obtenido de http://repositorio.dpe.gob.ec/handle/39000/71

32. García, W. (Agosto de 2017). Adaptaciones curriculares en las aulas de educación superior como base para la inclusión de estudiantes con discapacidad. Trabajo de titulación proyecto de investigación y desarrollo, previo a la obtención del grado académico de magíster en educación superior. Guayaquil, Ecuador: Universidad Católica de Santiago de Guayaquil. Recuperado de http://repositorio.ucsg.edu.ec/handle/3317/9104

33. Gil, S. (2018). La igualdad real y efectiva, ¿una realidad? Cuadernos de la Guardía Civil № 56. 2018. PÁGINAS 61-82. , 61-82. Recuperado de CUADERNOS DE LA GUARDIA CIVIL № 56. 2018. PÁGINAS 61-82. ISSN: 
2341-3263 61LA IGUALDAD REAL Y EFECTIVA, ¿UNA REALIDAD?SILVIA GIL CERDÁ.

34. Hurtado, L., \& María, A. (2014). Inclusión educativa de las personas con discapacidad en Colombia. Revista CES Movimiento y Salud , 45-55. Recuperado de http://riberdis.cedd.net/bitstream/handle/11181/4889/Inclusion_educativa_de_las 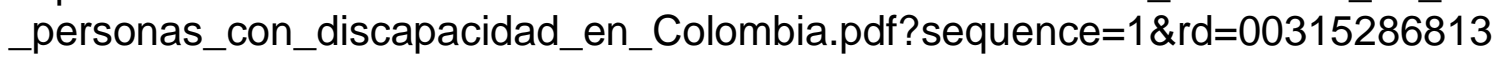 43660

35. Jara, R., Melero, N., \& Guichot, E. (julio-diciemebre de 2015). Inclusión socioeducativa, perspectivas y desafíos: Universidad Politécnica Salesiana del Ecuador y Universidad de Sevilla-España. Alteridad. Revista de Educación, Vol. 10, No. 2, 164-179. Recuperado de https://dspace.ups.edu.ec/handle/123456789/13758

36. Justel, D. (diciembre de 2012). Niños en la antigüedad: Estudio sobre la infancia en el mediterraneo antiguo. Zaragoza: Prensas de la Universidad de Zaragoza. Recuperado de https://books.google.es/books?hl=es\&lr=lang_es\&id=B_b3p4nhlqUC\&oi=fnd\&pg= PA9\&dq=como+eran+vistos+los+ni\%C3\%B1os+y+su+derechos+en+la+antigued ad\&ots $=$ Im7jB8b_lh\&sig=dVA3xcmLAYX2XYYaqidKB3r41Rw\#v=onepage \&q\&f=false

37. Ley Orgánica de Discapacidades. (2012). Ley Orgánica de Discapacidades.

38. Ley Orgánica de Educación Superior. (2010). Ley Orgánica de Educación Superior. Quito.

39. Liebel, M., Martínez, M., Recknagel, A., Cussiánovich, A., Figueroa, E., Sauri, G., Bazán, J. (2008). deOa18.net. Recuperado de de0a18.net/pdf/doc_participacio_infancia_derechos_humanos.pdf\#page=23

40. Llano, J. (2017). Teoría del derecho, neoconstitucionalismo y derechos diferenciados. Revista Verba luris, 13-32. Recuperado de https://doi.org/10.18041/0121-3474/verbaiuris.38.1051

41. Maldonado, V. (29 de marzo de 2013). El modelo social de la discapacidad: una cuestión de derechos humanos. Boletín mexicano de derecho comparado. Obtenido de http://www.scielo.org.mx/scielo.php?script=sci_arttext\&pid=S0041 $86332013000300008 \& \operatorname{lng}=$ es\&tlng=pt. 
42. Mogrovejo Gavilanes, A. R., Erazo Álvarez, J. C., Pozo Cabrera, E. E., \& Narváez Zurita, C. I. (2020). Aplicación del Principio de proporcionalidad en la Jurisprudencia de la Corte Constitucional del Ecuador. Iustitia Socialis, 111.

43. Navarrete, M. (2017). Acerca de nostros: nexus.univalle.edu.co. Obtenido de http://nexus.univalle.edu.co/index.php/historia_y_espacio/article/view/4567

44. Oficina del Alto Comisionado de las Naciones Unidas para los Derechos Humanos. (2012). Ecuador y el sistema de protección de derechos humanos de la ONU: sistematización de recomendaciones 2008-2012. Quito: Defensoría del Pueblo de Ecuador. Obtenido de http://repositorio.dpe.gob.ec/handle/39000/114

45.Palacios, A. (julio de 2008). El modelo social de discapacidad orígenes y plamación en la convención internacional sobre los derechos de las personas con discapacidad. Obtenido de books.google.com.mx/books?hl=es\&lr=\&id=VYlbqdLsrzUC\&oi=fnd\&pg=PA13\&dq =personas+con+discapacidad+mental+en+la+antiguedad+como+eran+considera dos,+tenian+derechos\&ots=PBn2rRa9AY\&sig=5S29_8_IzwTqRGABRNtn1sZkYU\#v=onepage\&q\&f=false

46. Rabbosi, E. (Septiembre - Noviembre de 1990). Derechos humanos: El principio de igualdad y la discriminación. Revista del Centro de Estudios Constitucionales, 7, 175-192. Obtenido de https://scholar.google.es

47. Ramírez, N. (2014). Derechos Humanos artículo investigativo. Trabajo de grado para optar por el título de abogado. Bogotá, Colombia. Obtenido de https://repository.ugc.edu.co/handle/11396/5082

48. Reglamento de Régimen Académico. (2019). Reglamento de Régimen Académico.

49. Reglamento de Régimen Académico Consejo de Educación Superior. (2013). Reglamento de Régimen Académico Consejo de Educación Superior.

50. Ricciardi, R., Hurault, R., \& Rodás, H. (2007). LA BIBLIA (Quinta reimpresión ed.). Venuezuela: Paulinas editorial es una versión apostólica de las hijas de San pablo.

Obtenido

de https://books.google.es/books?hl=es\& $\mid r=\& i d=2 v Q 9 N 7 P 8 T u A C \& o i=f n d \& p g=P A 3 \&$ $\mathrm{dq}=\mathrm{la}+$ Biblia+Ricciardi, $+\mathrm{R} \% 3 \mathrm{~B}+\mathrm{Hurault},+\mathrm{R} \% 3 \mathrm{~B}+\mathrm{Rod} \% \mathrm{C} 3 \% \mathrm{~A} 1 \mathrm{~s},+\mathrm{H} \% 3 \mathrm{~B} \&$ ots $=\mathrm{us}$ PG13vXXh\&sig=ehtNvGYiD5Axx8Mk2dli6rTwZy4\#v=onepage\&q\&f=false

51. Schalock, R. (2009). La nueva definición de discapacidad intelectual, apoyos individuales y resultados personales. (FEAPS, Ed.) Siglo cero, revista española 
Iustitia Socialis. Revista Arbitrada de Ciencias Jurídicas.

Año V. Vol. V. N 1 . Edición Especial. 2020

Hecho el depósito de Ley: FA2016000064

ISSN: $2542-3371$

FUNDACIÓN KOINONIA (F.K). Santa Ana de Coro, Venezuela

Fátima Piedad Gutiérrez-Mejía; Cecilia Ivonne Narváez-Zurita; Cornelio Agustín Borja-Pozo; Juan Carlos Erazo-Álvarez

sobre la discapacidad intelectual, 40 (1), 22-39. Obtenido de http://hdl.handle.net//11181/3841

52. Schalock, R. L. (2009). La nueva definición de discapacidad intelectual, apoyos individuales y resultados personales. SIGLO CERO, Volumen 40 (1) Núm 229, 22-39.

(C)2020 por los autores. Este artículo es de acceso abierto y distribuido según los términos y condiciones de la licencia Creative Commons Atribución-NoComercial-Compartirlgual 4.0 Internacional (CC BY-NC-SA 4.0) (https://creativecommons.org/licenses/by-nc-sa/4.0/). 